\title{
Effect of Intra-Venous Versus Intra-Arterial Leptin Infusion on Blood Pressure and Heart Rate
}

\author{
Khalid F. Talafih ${ }^{1}$, Mohamad Mousa J. Mohamad ${ }^{1}$, Mukhallad A. Mohammad ${ }^{*}, 1$ and \\ Zeyad J. El-Akawi \\ ${ }^{1}$ Department of Physiology/Faculty of Medicine, Jordan University of Science and Technology, Irbid 22110, Jordan; \\ ${ }^{2}$ Department of Biochemistry and Molecular Biology/Faculty of Medicine, Jordan University of Science and Technol- \\ ogy, Irbid 22110, Jordan
}

\begin{abstract}
Objectives: In this study the effects of different Leptin concentrations on the blood pressure and heart rate in vivo in anesthetized rabbits were studied.

Methods: Sixty Rabbits were divided into two groups, first group received Leptin intra-venously and other group received Leptin intra-arterially. Blood pressure and heart rate in were recorded before and after administration of Leptin.

Results: A significant increase in mean arterial blood pressure (MABP) was seen after an intra-arterial injection of 3, 5 and $7 \mu \mathrm{g} / \mathrm{kg}$ of Leptin. This increase in MABP was monitored for different durations 10, 20 and 30 minutes after the infusion of each Leptin concentrations. The trend of the increase in MABP with time was demonstrated with all three concentrations. Intra-venous infusion of Leptin caused a significant decrease in MABP after 10 minutes as well as after 20 and 30 minutes, with all three concentrations $(3,5$, and $7 \mu \mathrm{g} / \mathrm{Kg})$. Heart rate (HR) was not changed significantly at the end of 30 min of infusion.

Conclusion: this in vivo study demonstrated that intra-venous Leptin infusion has a different effect on the MABP compared with intra-arterial infusion and this difference might be due to the site of action of Leptin.
\end{abstract}

Keywords: Leptin, cardiovascular, blood pressure, heart rate.

\section{INTRODUCTION}

Leptin is a polypeptide hormone synthesized in white adipose tissues and encoded by the ob gene [1]. It plays an important role in the energy balance. This Leptin effect is taking place by its interaction with specific hypothalamic receptors affecting appetite and satiety centers of the brain in a feedback loop [2-4]. Administration of Leptin to mice causes a decrease in food intake, weight loss and an increase in energy expenditure [5-7]. Leptin effects on the cardiovascular system include elevation in blood pressure [8] and vasodilatation [9]. For example, the increase in blood pressure might be caused by increasing the heart rate and vasoconstriction through the sympathetic effect of Leptin $[8,10$ 12]. In contrast, the vasodilatation effect of Leptin modulated through a local mechanism involving nitric oxide (NO) release [9,13-15]. Recent study by Mohamad et al., on the effect of Leptin on isolated rat mesenteric arteries demonstrated that, the administration of Leptin induces relaxation of vascular smooth muscle through an endotheliumdependent release of nitric oxide (EDNO). In the same study, they also showed that the vascular effect was abolished by

*Address correspondence to this author at the Department of Physiology/Faculty of Medicine, Jordan University of Science and Technology, Irbid 22110, Jordan; Tel: Office: (02) - 7201000: Ext: (23671). Cell: (079) 5158960; Fax: 962-2-7201064; E-mail: mukmoh@just.edu.jo administration of NO synthase blocker L-nitol-L-arginine methyl ester (L-NAME) [16]. A significant correlation between blood pressure and plasma Leptin concentration in patients with essential hypertension was demonstrated [17]. It was also demonstrated that high plasma Leptin concentration might be involved in the development of cardiovascular diseases including myocardial infarction in obese people [18]. In animal module, Shek et al. had shown that chronic administration of high Leptin both intra-arterially or intravenously causes increased in blood pressure and heart rate [19].

The aim of this study was to find the effect of different Leptin concentrations on the cardiovascular system (heart rate and blood pressure) in vivo in anesthetized rabbits. Using different concentrations of Leptin infused through the veins and arteries.

\section{METHODS}

This study was approved by scientific research committee at Jordan University of Science and Technology and ethical approval by medical faculty research committee. Sixty New Zealand white adult rabbits of either sex, weight ranged between 1.5 and $2.5 \mathrm{Kg}$ were used in this study. Rabbits were divided into two groups (A and B), each group was consisting of thirty rabbits. Leptin was administered intraarterially in rabbits of group A (three subgroups;A1,A2,A3 each consists of 10 animals and each one received different leptin concentration) while it infused intra-venously in rab- 
bits of group B (three subgroups;B1,B2,B3 consisting 10 animals each which received different leptin concentration). Rabbits, in the beginning of each experiment, were anesthetized with sodium pentobarbital (Abbott Laboratories, Abbott Park, Illinois U.S.A.), $30 \mathrm{mg} / \mathrm{Kg}$ body weight, via the circumflex ear vein. A polyethylene catheter was inserted into the right carotid artery through which Leptin was injected and the measurement of blood pressure and heart rate were recorded by pressure transducer (Washington PT400). The MABP was calculated by this equation: $\mathrm{MAPB}=1 / 3$ of systolic $\mathrm{BP}+2 / 3$ diastolic BP. Another catheter was inserted into the right femoral vein for Leptin infusion in B group and to obtain blood samples for $\mathrm{pH}$ testing. To maintain eucapnia, trachea was cannulated and artificial respiration was instituted during the whole experiment on the rabbits. At the start of each experiment after the surgery was performed and the tubes were placed, blood pressure and heart rate were recorded via the catheter that has been inserted into the right carotid artery using Harvard Universal Oscillograph with ECG.

In the first group (Group A) Leptin hormone was infused in one shot via the carotid artery in different concentrations as follows. Subgroup A1 received $3 \mu \mathrm{g} / \mathrm{Kg}$, subgroup A2 received $5 \mu \mathrm{g} / \mathrm{Kg}$ and subgroup $\mathrm{A} 3$ received $7 \mu \mathrm{g} / \mathrm{Kg}$ of Leptin. In the second group (group B), Leptin hormone was infused via the femoral vein in the following concentration 3 , 5 and $7 \mu \mathrm{g} / \mathrm{Kg}$ to B1, B2 and B3 subgroups, respectively. Leptin was obtained from Diagnostic System Laboratories INC. Webester/NY, U.S.A. After the administration of Leptin to both groups, blood pressure and heart rate were measured at different time points 10,20 and 30 minutes. The $\mathrm{pH}$ was monitored during all experiments to make sure that anesthetized rabbits have good ventilation. In statistical analysis, independent t-test and ANOVA tests were used. A value of $\mathrm{P} \leq 0.05$ was considered statistically significant.

\section{RESULTS}

Table 1 demonstrates the response of mean arterial blood pressure (MABP) to Leptin infusion and summarizes the baseline values for MABP before and after intra-arterial and intra-venous infusion of different doses of Leptin. A significant increase in MABP was seen after the intra-arterial injection of 3,5 and $7 \mu \mathrm{g} / \mathrm{kg}$ of Leptin. This increase in MABP was seen 10 minutes after the infusion of each Leptin concentrations and persisted after 20 and 30 minutes after the infusion of Leptin. The trend of the increase in MABP with time was demonstrated with all three concentrations. As shown in Table 1, we started to see the Leptin effect as early as 10 minutes after the administration of all three concentrations. The average of the increase in MABP at the end of the first 10 minutes with these concentrations compared with baseline BP was about $5.3 \pm 0.6 \mathrm{~mm} \mathrm{Hg}$. This increase was also demonstrated at the end of 20 and 30 minutes after infusion, the average of the increase was $6.7 \pm 1.5$ and $9.3 \pm 0.6$ $\mathrm{mm} \mathrm{Hg}$ respectively compared with controls. The differences in the average increment between 10 and $20 \mathrm{~min}$ and between 20 and $30 \mathrm{~min}$ were $1.3 \pm 1.2$ and $2.3 \pm 1.5 \mathrm{~mm} \mathrm{Hg}$ respectively. As shown in Table $\mathbf{1}$, the most increase in MABP takes place during the first 10 minutes after the drug infusion. If we compare the MABP 30 minutes after infusion with baseline blood pressure for all three concentrations we will find that the increase is statistically significant. This increase was from $65 \pm 4$ to $75 \pm 8 \mathrm{~mm} \mathrm{Hg}$ (P-value $=$ $0.003), 66 \pm 7$ to $75 \pm 8 \mathrm{~mm} \mathrm{Hg}(\mathrm{P}$-value $=0.001)$ and from $66 \pm 10$ to $75 \pm 9 \mathrm{~mm} \mathrm{Hg}(\mathrm{P}$-value $=0.001)$ for the concentrations of 3,5 , and $7 \mu \mathrm{g} / \mathrm{kg}$ respectively. It is also shown in Table 1 that intra-venous infusion of Leptin resulted in a significant decrease in MABP after 10 minutes as well as after 20 and 30 minutes at all three concentrations $(3,5$, and $7 \mu \mathrm{g} / \mathrm{Kg}$ ), with P-values equal to $0.002,0.002$ and 0.011 respectively. The obvious decrease in MABP was noted at the end of the first 10 minutes followed by a trend of decrement in the rest of the experimental time, up to 30 minutes.

The response of the heart rate (HR) to Leptin infusion is demonstrated in Table 2. Results were taken at the end of 30 minutes after intra-venous and intra-arterial Leptin infusion in three concentrations 3,5 , and $7 \mu \mathrm{g} / \mathrm{Kg}$. As shown in the table, the HR was increased at the end of $30 \mathrm{~min}$ of infusion but this increment was not statistically significant compared with the base line values.

Table 1. The Response of the Mean Arterial Blood Pressure (MABP) in (mmhg) on Intra-Arterial and Intra-Venous Infusion of Leptin at Different Concentrations $(3,5$, and $7 \mu \mathrm{g} / \mathrm{Kg}$ ) Compared with Baseline Readings. P Value is Different Between Baseline Reading and Last Reading

\begin{tabular}{|c|c|c|c|c|c|}
\hline $\begin{array}{c}\text { Leptin } \\
\text { Concentrations }\end{array}$ & Baseline BP Mmhg & BP After $10 \mathrm{~min}$ & BP After $20 \mathrm{~min}$ & BP After 30 min & P-Value \\
\hline \multicolumn{6}{|c|}{ Intra-arterial Infusion (group A) } \\
\hline $3 \mu \mathrm{g} / \mathrm{Kg}$ & $65 \pm 4$ & $71 \pm 6$ & $73 \pm 6$ & $75 \pm 8$ & 0.003 \\
\hline $5 \mu \mathrm{g} / \mathrm{Kg}$ & $66 \pm 7$ & $71 \pm 6$ & $72 \pm 6$ & $75 \pm 8$ & 0.001 \\
\hline \multicolumn{6}{|c|}{ Intra-venous Infusion (group B) } \\
\hline $3 \mu \mathrm{g} / \mathrm{Kg}$ & $74 \pm 10$ & $70 \pm 11$ & $66 \pm 9$ & $64 \pm 7$ & 0.002 \\
\hline $5 \mu \mathrm{g} / \mathrm{Kg}$ & $80 \pm 5$ & $72 \pm 8$ & $69 \pm 6$ & $68 \pm 8$ & 0.002 \\
\hline $7 \mu \mathrm{g} / \mathrm{Kg}$ & $78 \pm 9$ & $74 \pm 8$ & $69 \pm 8$ & $68 \pm 8$ & 0.011 \\
\hline
\end{tabular}


Table 2. The Response of the Heart Rate (HR) on Intra-Arterial and Intra-Venous Infusion of Leptin at Different Concentrations $(3,5$, and $7 \mu \mathrm{g} / \mathrm{Kg})$ Compared with Baseline Readings

\begin{tabular}{|c|c|c|c|c|}
\hline Leptin Concentration & Baseline Heart Rate beats/Minute & Heart Rate Beats/Minute After 30 min & P-Value \\
\hline \hline \multicolumn{5}{|c|}{ Intra-arterial infusion (group A) } \\
\hline $3 \mu \mathrm{g} / \mathrm{Kg}$ & $273 \pm 40$ & $283 \pm 28$ & 0.44 \\
\hline $5 \mu \mathrm{g} / \mathrm{Kg}$ & $273 \pm 35$ & $272 \pm 35$ & 0.74 \\
\hline $7 \mu \mathrm{g} / \mathrm{Kg}$ & $266 \pm 42$ & $274 \pm 36$ & 0.26 \\
\hline \multicolumn{2}{|c|}{ Intra-venous infusion (group B) } \\
\hline $3 \mu \mathrm{g} / \mathrm{Kg}$ & $268 \pm 27$ & $266 \pm 26$ & 0.42 \\
\hline $5 \mu \mathrm{g} / \mathrm{Kg}$ & $274 \pm 30$ & $288 \pm 31$ & 0.07 \\
\hline $7 \mu \mathrm{g} / \mathrm{Kg}$ & $266 \pm 38$ & $273 \pm 36$ & 0.35 \\
\hline
\end{tabular}

\section{DISCUSSION}

Variable effects of Leptin on cardiovascular system were found in different studies. In the present study we demonstrated considerably new findings concerning the effect of Leptin on MABP. Intra-venous infusion of Leptin in anesthetized rabbits showed a significant decrease in MABP. This decrease in MABP could be due to the direct effect of Leptin on vascular endothelium that resulted in endotheliumdependent relaxation of small veins through the release of NO. This relaxation effect might increase the vascular capacitance and retained more blood in the small veins. The possible consequence of this effect is the reduction in cardiac filling followed by a decrease in cardiac output as well as blood pressure. This type of mechanism was demonstrated in a study performed by Hainsworth et al. [20]. Our findings are different from those previously obtained by other researchers. The changes in MABP that we demonstrated in the result of intra-venous Leptin administration to anesthetized rabbits were not developed in conscious rats and rabbits as previously declared. It was reported that intra-venous Leptin infusion in both conscious rabbits and rats did not affect blood pressure [21,22]. This discrepancy could be explained by more than one factor; the effect of anesthesia, the animal type, the status of the nervous system (animals being conscious or anesthetized) and the effect of Leptin effect whether on the sympathetic nervous system by increasing sympathetic activity or the direct effect on the vascular endothelium by increasing the synthesis of NO.

The significant increase in MABP after intra-arterial Leptin infusion that we were demonstrated in this study might be due to a central stimulation of sympathetic activity which caused vasoconstriction and consequently blood pressure elevation. These findings are consistent with what have been reported in the previous studies. It has been found that Leptin administered intra-cerebroventricularly or intravenously increases sympathetic nervous activity $[8,11,12]$. On the other hand our results, regarding the increase in MABP after intra-arterial Leptin infusion, are inconsistent with a reasonable number of studies where implicated Leptin as vasodilator of peripheral vessels in vitro [9,14,22-24]. The direct vasodilator response to Leptin contrast with vasoconstrictor responses resulting from increases in sympathetic efferent discharge which have been demonstrated when Leptin infused into both animal [8,12] and human [25].

It is also demonstrated by Knudson et al. that in anesthetized dogs intra-coronary Leptin infusion did not change coronary blood flow significantly [26]. They also reported that Leptin causes marked dilator response in isolated coronary arterioles. While other study on coronary blood vessels in human [27] reported that Leptin induces a dosedependent, NO independent increase in both coronary artery diameter and coronary blood flow.

In this study intra-arterial injection of Leptin causes increases in MABP obtained at 10, 20, 30 minutes after infusion which is consistent with other study by Matsumura et al. [21]. This experiment also demonstrates that intravenous or intra-arterial infusion of Leptin does not have significant effects on the heart rate in anesthetize rabbits. Possible explanations for this finding are; intra-venous infusion mostly cause direct effect on the blood vessels and induce relaxation, while intra-arterial infusion cause sympathetic stimulation but not always increase significantly heart rate in anesthetized animal. This finding also reported by other study, in rabbits with intra-cerebroventricular injection of Leptin elicited dose related increases of MABP but no consistent significant increase of heart rate [21]. Since the heart rate does not changed significantly with the changes of blood pressure after Leptin infusion by both ways, this raises the possibility the leptin is having other modulating effects on heart rate. Further studies are needed to see whether increased MAPB after intra-arterial Leptin infusion is due to increased peripheral resistance or other causes.

In conclusion this in vivo study demonstrated that Leptin exerts direct vasodilatory action by intra-venous infusion that lead to decrease MABP. While intra-arterial infusion increases peripheral blood vessels resistance and MABP through centrally acting sympathetic stimulation. But both intra-venous and intra-arterial infusion of Leptin did not significantly change the heart rate.

\section{ACKNOWLEDGEMENT}

This work was financially supported by Jordan University of Science and Technology. 


\section{REFERENCES}

[1] Zhang Y, Proenca R, Maffei M, Barone M, Leopold L, Friedman J. Positional cloning of the mouse obese gene and its human homologue. Nature 1994; 372: 425-32.

[2] Bray GA. Leptin and leptinomania. Lancet 1996; 348: 140-41.

[3] Sørensen TI, Echwald SM, Holm JC. Leptin in obesity. BMJ 1996; 313: 953-54.

[4] Rohner-Jeanrenaud F, Jeanrenaud B. Obesity, leptin, and the brain. N Engl J Med 1996; 334: 324-5.

[5] Campfield LA, Smith FJ, Guisez Y, Devos R, Burn P. Recombinant mouse $\mathrm{OB}$ protein: evidence for a peripheral signal linking adiposity and central neural networks. Science 1995; 269: 546-49.

[6] Halaas JL, Gajiwala KS, Maffei M, et al. Weight-reducing effects of the plasma protein encoded by the obese gene. Science 1995; 269: 543-46.

[7] Pelleymounter MA, Cullen MJ, Baker MB, et al. Effects of the obese gene product on body weight regulation in ob/ob mice. Science 1995; 269: 540-43.

[8] Dunbar JC, Hu Y, Lu H. Intra-cerebroventricular leptin increases lumbar sympathetic and renal sympathetic nerve activity and blood pressure in normal rats. Diabetes 1997; 46: 2040-43.

[9] Lembo G, Vecchione C, Fratta L, et al. Leptin induces direct vasodilatation through distinct endothelial mechanism. Diabetes 2000; 49: 293-97.

[10] Julius S, Valentini M, Palatini P. Overweight and hypertension a 2way street? Hypertension 2000; 35: 807-13.

[11] Haynes WG, Sivitz WI, Morgn DA, Walsh SA, Mark AL. Sympathetic and cardiorenal actions of leptin. Hypertension 1997; 30: 619-23.

[12] Rahmouni K, Haynes WG, Mark AL. Cardiovascular and sympathetic effects of leptin. Curr Hypertens Rep 2002; 4: 119-25.

[13] Bouloumie A, Drexler HCA, Lafontan M, Busse R. Leptin, the product of $\mathrm{Ob}$ gene, promotes angiogenesis. Circ Res 1998; 83: $1059-66$

[14] Kimura K, Tsuda K, Baba A, et al. Involvement of nitric oxide in endothelium-dependent arterial relaxation by leptin. Biochem Biophys Res Commun 2000; 273: 745-49.
[15] Vecchione C, Maffei A, Colella S, et al. Leptin effect on endothelial nitric oxide is mediated through Akt-endothelial nitric oxide synthase phosphorylation pathway. Diabetes 2002; 51: 168-73.

[16] Mohammed MJ, David SM, Lucy JH, Roger H, Mark JD. Effects of dietary salt loading on the responses of isolated rat mesenteric arteries to leptin. Am J Hypertens 2005; 18(4): 500-03.

[17] Agata J, Masuda A, Takada M, et al. High plasma immunoreactive leptin level in essential hypertension. Am J Hypertens 1997; 10: 1171-74

[18] Soderberg S, Ahren B, Jansson JH, et al. Leptin is associated with increased risk of myocardial infarction. J Intern Med 1999; 246(4): 409-18.

[19] Shek EW, Brands MW, Hall JE. Chronic lepti infusion increases arterial pressure. Hypertension 1998; 31: 409-14.

[20] Hainsworth R. Vascular capacitance its control and importance. Rev Physiol Biochem Pharmacol 1986; 105: 101-03

[21] Jennifer LM, Donald AM, Marcelo LC, Allyn LM, William IS, William GH. Does leptin stimulate nitric oxide to oppose the effects of sympathetic activation. Hypertension 2001; 38: 1081-86.

[22] Matsumura K, Abe I, Tsuchihashi T, Fujishima M. Central effects of leptin on cardiovascular and neurohormonal responses in conscious rabbits. Am J Physiol 2000; 278: 1314-20.

[23] Nakagawa K, Higashi Y, Sasaki S, Oshima T, Matsuura H, Chayama K. Leptin causes vasodilation in human. Hypertens Res 2002; 25: 161-65.

[24] Winters B, Mo Z, Brooks-Asplund E, et al. Reduction of obesity, as induce by leptin, reverses endothelial dysfunction in obese (Lep ob) mice. J Appl Physiol 2000; 89: 2382-90.

[25] Haynes WG, Morgan DA, Wash AL, Sivitz WI. Leptin increases sympathetic nerve activity to brown adipose tissue and kidney. FASEB J 1997; 11. (Abstract) A4.

[26] Knudson JD, Dincer UD, Zhang C, et al. Leptin receptors are expressed in coronary arteries, and hyperleptinemia causes significant coronary endothelial dysfunction. AJP, Heart Circ Physiol 2005; 289: 48-56.

[27] Matsuda K, Teragawa R, Fukuda Y, Nakagawa K, Higashi Y, Chayama K. Leptin causes nitric-oxide independent coronary vasodilatation in human. Hypertens Res 2003; 26: 147-52.

(C) Talafih et al.; Licensee Bentham Open.

This is an open access article licensed under the terms of the Creative Commons Attribution Non-Commercial License (http://creativecommons.org/licenses/by-nc/3.0/) which permits unrestricted, non-commercial use, distribution and reproduction in any medium, provided the work is properly cited. 